\title{
Crianças e adolescentes em abrigos: uma regionalização para Minas Gerais
}

\section{Children and adolescents in shelters: a regionalization to Minas Gerais State}

\author{
Frederico Poley Martins Ferreira*
}

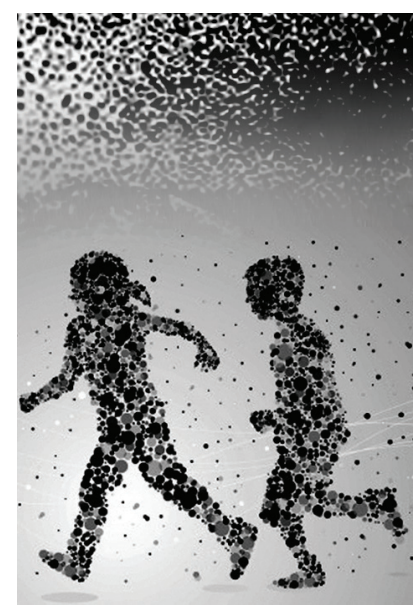

Resumo: No Brasil, as crianças abrigadas estão entre os segmentos mais vulneráveis da população. Uma pesquisa realizada em Minas Gerais, junto a todas instituições que prestam serviços de acolhimento no estado, permitiu identificar uma série de características desses jovens e também dos locais para onde foram encaminhadas. Nesse trabalho, procurou-se identificar e classificar os principais motivos de encaminhamento. Essas causas foram mapeadas, permitindo constatar distintas concentrações relativas nas várias regiões do estado. Foram elaboradas algumas hipóteses explicativas para a ocorrência dessas concentrações

Palavras-chave: Abrigos. Crianças e adolescentes. Minas Gerais.

\begin{abstract}
In Brazil fostered children/adolescents are among the most vulnerable segments of society. A survey in different institutions which provide shelter services to children/adolescents in Minas Gerais State identified those people's characteristics, as well as the characteristics of the places where they are sent to. We tried both to identify and to classify the main reasons why a child/adolescent is routed to an institution. Those reasons were mapped, revealing different relative concentrations in the several regions of the state. Hypotheses were developed to justify those concentrations.
\end{abstract}

Keywords: Shelters. Children and adolescents. Minas Gerais State.

* Doutor em Demografia. Pesquisador da Fundação João Pinheiro (FJP), Belo Horizonte/MG, Brasil. E-mail: frederico.poley@fjp.mg.gov.br. 


\section{Introdução}

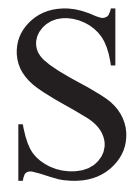

ão vários os motivos que levam uma criança ou adolescente para instituições que prestam serviços de abrigo. Da mesma maneira, as características individuais e o tempo em que elas permanecem acolhidas também variam muito. Porém um aspecto fundamental e comum a todas é que quando uma criança vai para um abrigo, mesmo que momentaneamente, há algum tipo de rompimento com suas famílias de origem. Sem dúvida, o rompimento familiar, mesmo que temporário, deveria ser considerado apenas como medida extrema.

Procurar entender melhor o que ocorre nas famílias ou os motivos que levaram essas crianças a ser abrigadas constitui um aspecto fundamental para a elaboração e a execução de políticas públicas mais eficazes e voltadas para o bem-estar presente e futuro dessas crianças.

A análise das consequências de políticas especificamente voltadas para as famílias ainda tem um caráter bastante incipiente no Brasil e em grande parte no mundo. Hoje, a maior parte dos estudos, nessa área, está relacionada aos impactos de programas e ações voltados para a transferência de renda para as famílias e suas condicionalidades. Porém, dada a própria complexidade do tema, ainda existe uma grande lacuna a ser preenchida. Dessa maneira:

Family policy has only recently, in the last decade or so enjoyed more attention from welfare state development theorists. The former lack of scholarly attention came about through policy development at the start of the industrial age, where an overwhelming amount of this policy affected women only indirectly. ${ }^{1}$ (Woods, 2012, p. 5)

A família está entre as primeiras instituições responsáveis pela socialização do ser humano. Portanto, pode-se concluir que as experiências na fase inicial da vida estão fundamentalmente envolvidas com suas experiências. Por sua vez, o ambiente familiar está entre os principais fatores para o desenvolvimento de atividades cognitivas e não cognitivas das crianças. Assim, crianças que crescem em ambientes saudáveis tendem a ter um desenvolvimento pleno das suas capacidades.

1. Políticas para as famílias, apenas recentemente e mais especificamente na última década tem recebido mais atenção dos teóricos que estudam o desenvolvimento dos estados de bem-estar. A falta de atenção inicial por parte da academia ocorreu junto com o entendimento de que o desenvolvimento de grande parte das políticas públicas, no início da era industrial, afetaria as mulheres apenas indiretamente. 
Da mesma forma, o desenvolvimento do indivíduo durante todas as fases de sua vida é cumulativo, ou seja, a carência de incentivos na infância e na adolescência pode acarretar maior dificuldade de desenvolvimento no futuro.

Os conflitos e os problemas intrafamiliares podem gerar certos eventos durante a vida dessas crianças, em que dadas determinadas circunstâncias, o encaminhamento para uma instituição provavelmente se tornaria uma alternativa para a satisfação de certas necessidades.

Nesse sentido e especificamente para o caso das crianças nas ruas, desde os anos 1970: “[...] researchers began demonstrating that young people living on the streets have extensive histories of familial abuse and neglect; leaving home is one of the few options they have to escape from maltreatment"2 (Hyde, 2005, p. 173).

Ao contrário da noção tradicional de "família", que assume que seria local de cuidados e suporte, muitas famílias são normalmente caracterizadas pelos conflitos entre pais e filhos, problemas de disciplina, falta de comunicação, falta de cuidados e supervisão, abusos físicos e sexuais, falta de afeição e carinho. Além disso, alguns outros assuntos frequentemente menos abordados pela literatura incluem conflitos relacionados à sexualidade e orientação sexual dos adolescentes, gravidez, uso de álcool e drogas por parte dos jovens (Hyde, 2005).

Por sua vez, a maneira como ambiente familiar se desenvolve pode ser muito influenciada por fatores externos, como pelas características da comunidade ou da região na qual está localizada. Nesse caso, aspectos do mercado de trabalho regional, do nível de violência, da existência ou não de determinados serviços (educação, saúde, esporte e lazer), bem como da existência ou não do tráfico de drogas podem influenciar muito o comportamento das famílias e, consequentemente, sua relação com as crianças e os adolescentes.

Logicamente, entender como as diferentes características das crianças, de suas famílias e de suas comunidades, se interagem no sentido de resultar num processo de encaminhamento para um abrigo é extremamente complexo. Porém os dados obtidos pela pesquisa realizada nas instituições de acolhimento em Minas Gerais podem lançar luz sob alguns desses aspectos, incluindo-se a possibilidade de uma ótica "regional", o que possibilita o desenvolvimento de inferências e hipóteses. De forma geral, essa pesquisa forneceu subsídios detalhados tanto a respeito do que se refere às características das instituições (localização, tipos de serviços prestados, organização etc.), quanto informações das crianças abrigadas e dos motivos que

2. Pesquisadores começaram a demonstrar que os jovens que vivem nas ruas possuem extensas histórias de abuso familiar e negligência; sair de casa é uma das poucas opções que eles tem a serem maltratados. 
culminaram com essa medida. Foi possível identificar a existência de alguns padrões espaciais e regionais que poderiam influenciar certas causas de encaminhamentos.

É importante observar que, na grande maioria dos casos, os motivos que demandam o encaminhamento para um abrigo não ocorrem de maneira isolada. Por exemplo, o abandono, ou a negligência, muitas vezes vem acompanhado de um histórico famíliar com outros tipos de problemas.

Grande parte dessas famílias acaba vivenciando situações relacionadas e de forma concomitante à pobreza, à violência sexual, ao uso de drogas por parte dos pais e ou mesmo dos jovens. Sem dúvida, aqui as características familiares e regionais em que essas crianças estão inseridas possuem um vínculo fundamental com as causalidades que determinam um procedimento de abrigamento.

\section{Os dados}

Entre os anos de 2009 e 2010 foi realizada a Pesquisa Abrigos em Minas Gerais (FJP, 2009). O principal objetivo desse trabalho foi identificar instituições que prestam algum tipo de serviços de acolhimento em todo o estado para crianças e adolescentes com até dezoito anos incompletos. Não foram incluídas, no levantamento, creches, escolas (semi-internatos) instituições que aplicavam medidas socioeducativas e nem instituições de caráter terapêutico (por exemplo, comunidades terapêuticas para o tratamento de drogas). O público-alvo da pesquisa foram todas as instituições que ofereciam acolhimento continuado a crianças e adolescentes desacompanhados de seus familiares, o que pressupunha a regularidade nos serviços oferecidos e determinava ao dirigente da instituição a equiparação legal ao guardião dos meninos e das meninas acolhidos (Silva, 2004).

Foi aplicado um questionário com 43 perguntas divididas em quatro blocos que, entre outros aspectos, procurou desvendar: as características administrativas das instituições, seu relacionamento com outros órgãos, formas de encaminhamento das crianças, metodologias e formas de atendimento, as maneiras como as crianças se relacionavam com a família e com a comunidade, além de algumas características das próprias crianças e adolescentes, como idade, tempo e o motivo do encaminhamento.

Especificamente neste artigo, procurou-se agrupar os dados a partir das regiões de planejamento do estado de Minas Gerais (num total de onze regiões, incluindo-se a região metropolitana de Belo Horizonte - RMBH). Os motivos de encaminhamentos foram ordenados em dezessete grupos principais. 


\section{Discussão}

Em novembro de 2009, data de referência da pesquisa, Minas Gerais possuía aproximadamente 5.101 crianças abrigadas em 352 instituições.

A região metropolitana de Belo Horizonte concentrava o maior número de abrigados e também de instituições, sendo também a mais densamente povoada do estado.

A segunda região com maior quantidade de crianças foi a da Zona da Mata mineira, que ocupa a terceira posição em relação à concentração populacional no estado, seguida pela região norte, que, por sua vez, é a quinta região mais povoada do estado. O sul de Minas, segunda região mais densamente povoada, concentrava a terceira maior quantidade de crianças abrigadas.

Considerando-se esses aspectos, pode-se observar que existe uma considerável variação em algumas regiões em relação à participação relativa do total de crianças e jovens abrigados. Nem sempre essa variação acompanha a concentração populacional nessas áreas. Vide Tabela 1 e Mapas 1 e 2.

Tabela 1. Distribuição da população total e total de crianças em abrigos por regiões de planejamento de Minas Gerais. 2009-2010

\begin{tabular}{|l|c|c|c|c|}
\hline $\begin{array}{c}\text { Regiões de } \\
\text { Planejamento }\end{array}$ & $\begin{array}{c}\text { População } \\
\mathbf{2 0 1 0}\end{array}$ & $\begin{array}{c}\text { \% população } \\
\mathbf{2 0 1 0}\end{array}$ & $\begin{array}{c}\text { Total de crianças } \\
\text { abrigadas } \\
\mathbf{2 0 0 9}\end{array}$ & $\begin{array}{c}\text { \% de crianças } \\
\text { abrigados } \\
\mathbf{2 0 0 9}\end{array}$ \\
\hline Alto Paranaíba & 655.353 & 3,34 & 214 & 4,2 \\
\hline Região central & 6.971 .049 & 35,57 & 1663 & 32,6 \\
\hline Centro-Oeste de Minas & 1.120 .202 & 5,72 & 199 & 3,9 \\
\hline Jequitinhonha/Mucuri & 1.002 .119 & 5,11 & 377 & 7,4 \\
\hline Zona da Mata & 2.173 .374 & 11,09 & 602 & 11,8 \\
\hline Noroeste de Minas & 366.418 & 1,87 & 71 & 1,4 \\
\hline Norte de Minas & 1.610 .413 & 8,22 & 541 & 10,6 \\
\hline Rio Doce & 1.620 .993 & 8,27 & 515 & 10,1 \\
\hline Sul de Minas & 2.588 .280 & 13,21 & 531 & 10,4 \\
\hline Triângulo & 1.489 .129 & 7,60 & 388 & 7,6 \\
\hline Minas Gerais & 19.597 .330 & 100.0 & 5.101 & 100,0 \\
\hline
\end{tabular}

Fonte: IBGE, Censo Demográfico 2010. 


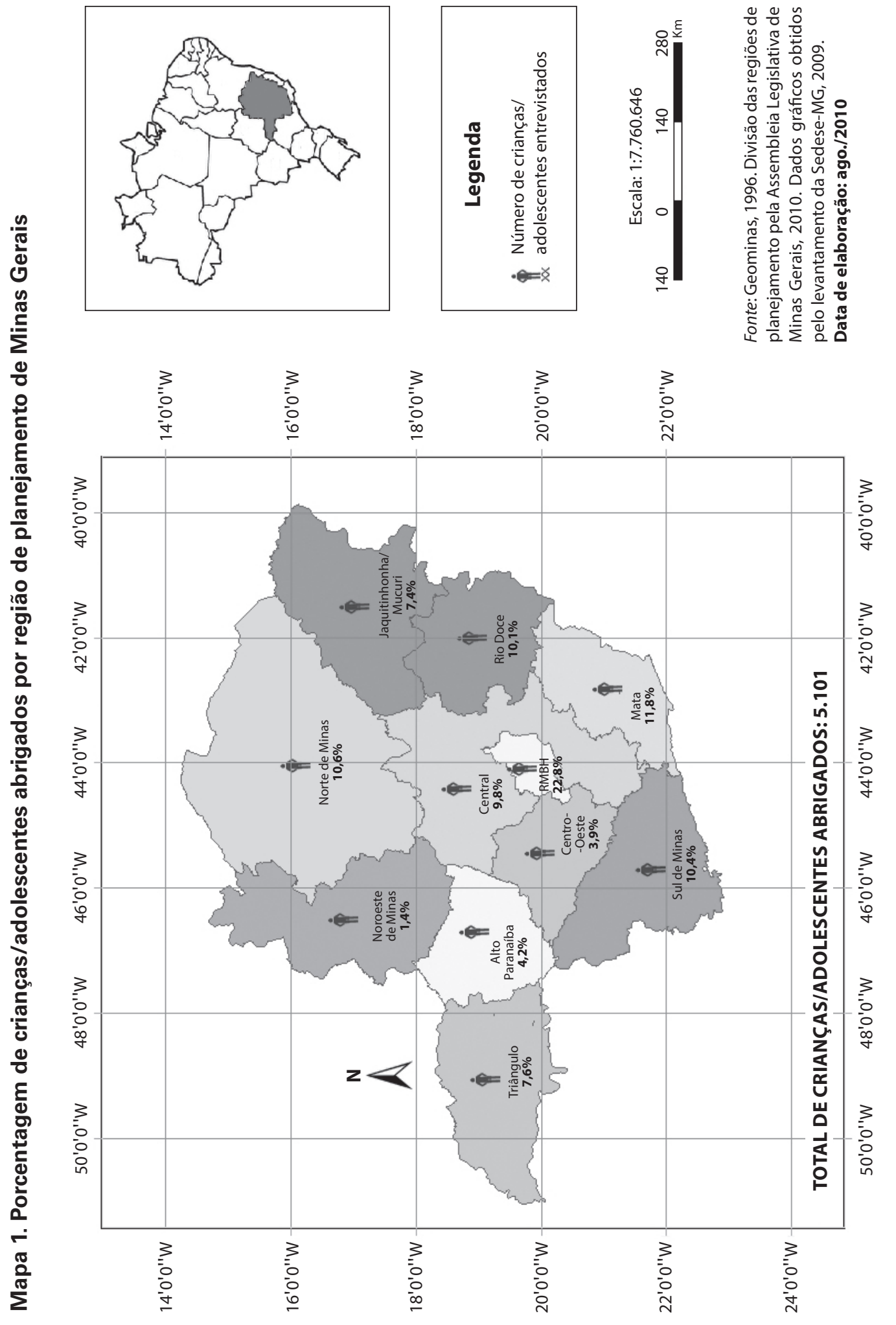




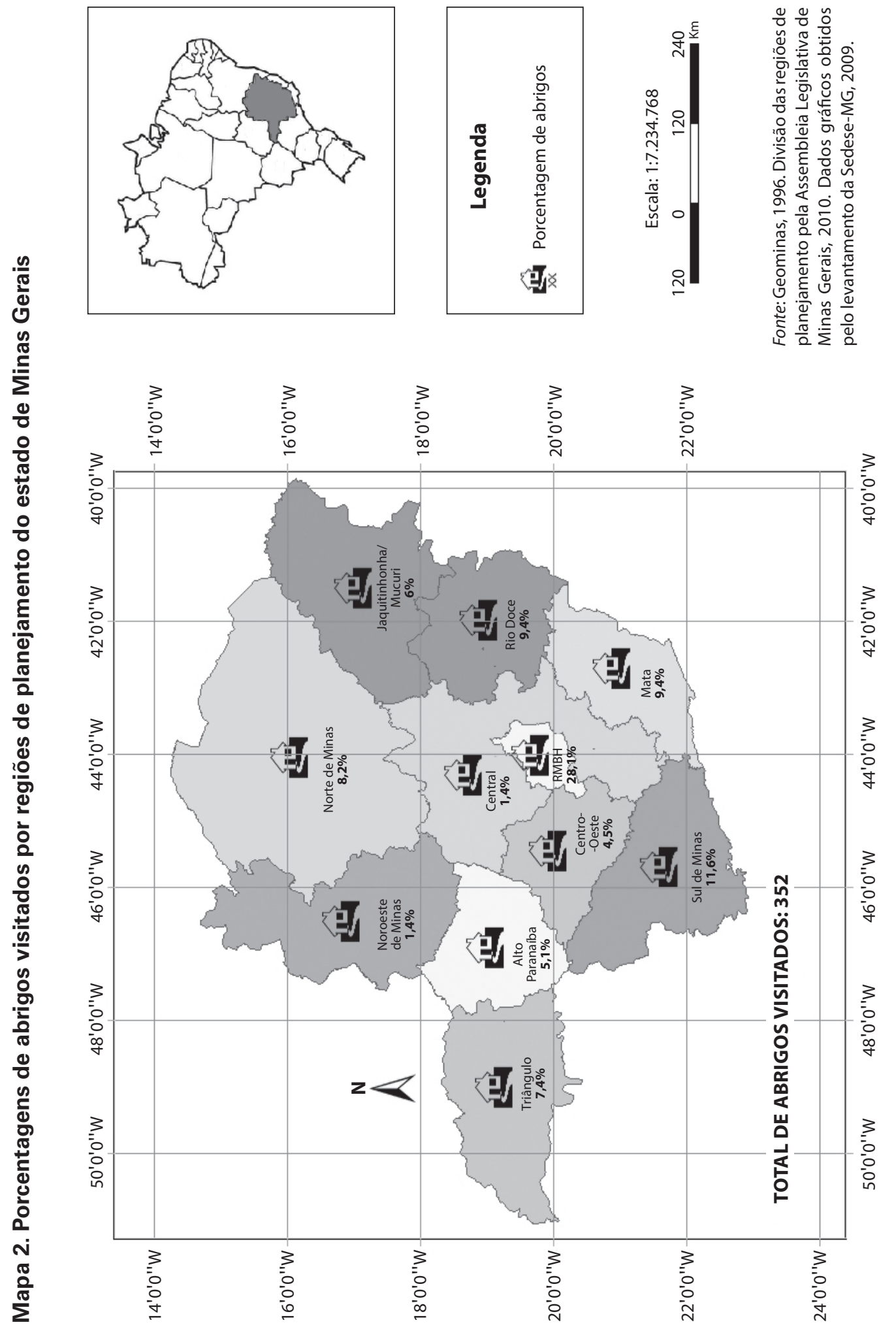


Com relação à distribuição das instituições por regiões de planejamento, como já observado, a região metropolitana de Belo Horizonte concentrava o maior número relativo, seguida pelas regiões sul de Minas e Vale do Rio Doce. A Zona da Mata que concentrava o segundo maior porcentual de crianças abrigadas em termos relativos, no que se refere ao número de abrigos, ocupou a quarta posição, sugerindo que existe nessa região um menor número de instituições, porém de maior porte. O mesmo pode-se dizer em relação à região norte do estado, que possui relativamente mais crianças do que instituições.

Dessa maneira, a pesquisa revelou uma grande variação no porte dessas organizações, o que pode ser observado na Tabela 2. Mais da metade dos abrigos possuem capacidade máxima para até quinze crianças. Porém no estado ainda existem instituições de grande porte, algumas possuindo vagas para mais de cem crianças.

Tabela 2. Capacidade máxima do abrigo em uma noite - Instituições de Minas Gerais 2009

\begin{tabular}{|c|c|c|}
\hline Capacidade & Frequência & $\%$ \\
\hline $1-15$ & 189 & 53,69 \\
\hline $16-50$ & 137 & 38,92 \\
\hline $51-100$ & 9 & 2,56 \\
\hline $101-150$ & 5 & 1,42 \\
\hline+150 & 3 & 0,85 \\
\hline Sem informação & 9 & 2,56 \\
\hline Total & 352 & 100 \\
\hline
\end{tabular}

Fonte: Fundação João Pinheiro, 2009. 


\section{Os motivos de abrigamento}

Como já observado, as razões que levam uma criança para um abrigo se sobrepõem, ou seja, normalmente existem mais de um motivo que justifica sua saída do ambiente familiar. $\mathrm{O}$ abandono, ou a negligência, por exemplo, muitas vezes vem acompanhado de um histórico famíliar com problemas. Grande parte dessas famílias acaba vivenciando situações relacionadas à pobreza, à violência sexual, ao uso de drogas por parte dos pais e/ou mesmo dos jovens. Sem dúvida, aqui as características familiares em que essas crianças estão inseridas possuem um vínculo fundamental com as causalidades que determinam um procedimento de abrigamento.

Porém, no intuito de se mapear esses motivos, procurou-se utilizar para fins de análise sempre a primeira razão declarada no momento da entrada da criança na instituição ou o motivo principal que gerou o encaminhamento, registrado nos prontuários da instituição entrevistada. Por sua vez, entre os motivos principais para análise e mapeamento, foram selecionadas as frequências que apresentaram uma proporção superior a $4 \%$ das respostas válidas em todo o estado.

Os quatro principais motivos que levaram as crianças para as instituições, mesmo que temporariamente, foram: a negligência, o abandono, os maus-tratos e o alcoolismo dos pais ou responsáveis. Apenas esses quatro representaram 58,28\% da frequência total dos primeiros motivos de encaminhamento em Minas Gerais, como pôde ser observado na Tabela 3 .

Dessa maneira, foram mapeados e analisados os motivos: negligência, abandono, maus-tratos/violência doméstica, alcoolismo dos pais e responsáveis, situação de risco e vulnerabilidade social, abuso suspeita de violência sexual, uso e tráfico de drogas por parte dos pais e responsáveis. A partir da frequência total, por motivo principal, os porcentuais de concentração foram calculados e mapeados para cada região de planejamento do estado, conforme sua ocorrência.

Como poderá ser observado, constatou-se que alguns motivos, apresentaram uma concentração relativa em determinadas regiões muito superior às demais. 
Tabela 3. Distribuição dos principais motivos/encaminhamentos para instituições de abrigo no estado de Minas Gerais - 2009

\begin{tabular}{|c|c|}
\hline Principal/Primeiro motivo & $\%$ \\
\hline 1. Negligência & 21,08 \\
\hline 2. Abandono & 15,47 \\
\hline 3. Maus-tratos/violência doméstica/agressão física, contra a criança ou adolescente & 12,83 \\
\hline 4. Alcoolismo dos pais/responsáveis & 8,99 \\
\hline 5. Situações de risco/vulnerabilidade social, física, psicológica, moral, habitacional & 7,66 \\
\hline 6. Abuso/suspeita/tentativa de violência sexual, ou prostituição infantil & 5,61 \\
\hline 7. Uso/tráfico de drogas por parte dos pais/responsável & 4,51 \\
\hline $\begin{array}{l}\text { 8. Ausência dos pais ou responsáveis devido a prisão/desaparecimento/internação } \\
\text { hospitalar(ou psiquiátrica) }\end{array}$ & 3,92 \\
\hline 9. Carência socioeconômica (pobreza) & 3,1 \\
\hline 10. Medida de proteção/segurança; ou decisão/ordem/encaminhamento judicial & 2,84 \\
\hline 11. Orfandade (falecimento do pai e mãe) & 2,54 \\
\hline 12. Vivência/situação/trajetória de rua (família e/ou criança) & 1,97 \\
\hline 13. Uso de drogas/tráfico de drogas, por parte da criança ou adolescente & 1,28 \\
\hline 14. Ameaça à vida da criança e do adolescente & 0,69 \\
\hline 15. É agressor/infrator ou constitui ameaça à comunidade & 0,64 \\
\hline $\begin{array}{l}\text { 16. Doenças/deficiências físicas, mentais, de cognição/comportamento, da criança ou } \\
\text { adolescente }\end{array}$ & 0,26 \\
\hline 17. Outros motivos & 6,63 \\
\hline Total & 100,0 \\
\hline
\end{tabular}

Fonte: FJP, 2009. 


\section{Negligência}

De acordo com dados da pesquisa, a negligência é o principal motivo de encaminhamento das crianças para uma instituição em Minas Gerais. Entende-se por negligência a falta de cuidado, a indiferença, do responsável, que, podendo tomar as cautelas exigíveis, não o faz por displicência ou por outros motivos (Mirabete, 1980, p. 147).

As regiões que concentram o maior número de crianças que tiveram esse motivo como causa foram: a região metropolitana de Belo Horizonte (RMBH), seguida pela Zona da Mata e o centro-oeste de Minas, sendo que somente a RMBH concentrou mais de $25 \%$ dos casos.

A maneira como esse motivo específico se distribui no estado pode sugerir a necessidade de uma análise mais profunda e detalhada do que vem ocorrendo nas famílias e a adoção de medidas adequadas para essas áreas, no sentido de se reduzir essa motivação.

Um aspecto importante nesse aspecto é a necessidade de se desvincular a ideia de pobreza com a de negligência, muitas vezes consideradas em conjunto. Nesse caso, existem muitas crianças provenientes de famílias com condições socioeconômicas adequadas que também sofrem com esse problema. A pobreza pode agravar, mas não é motivo suficiente para uma criança ser "negligenciada". 


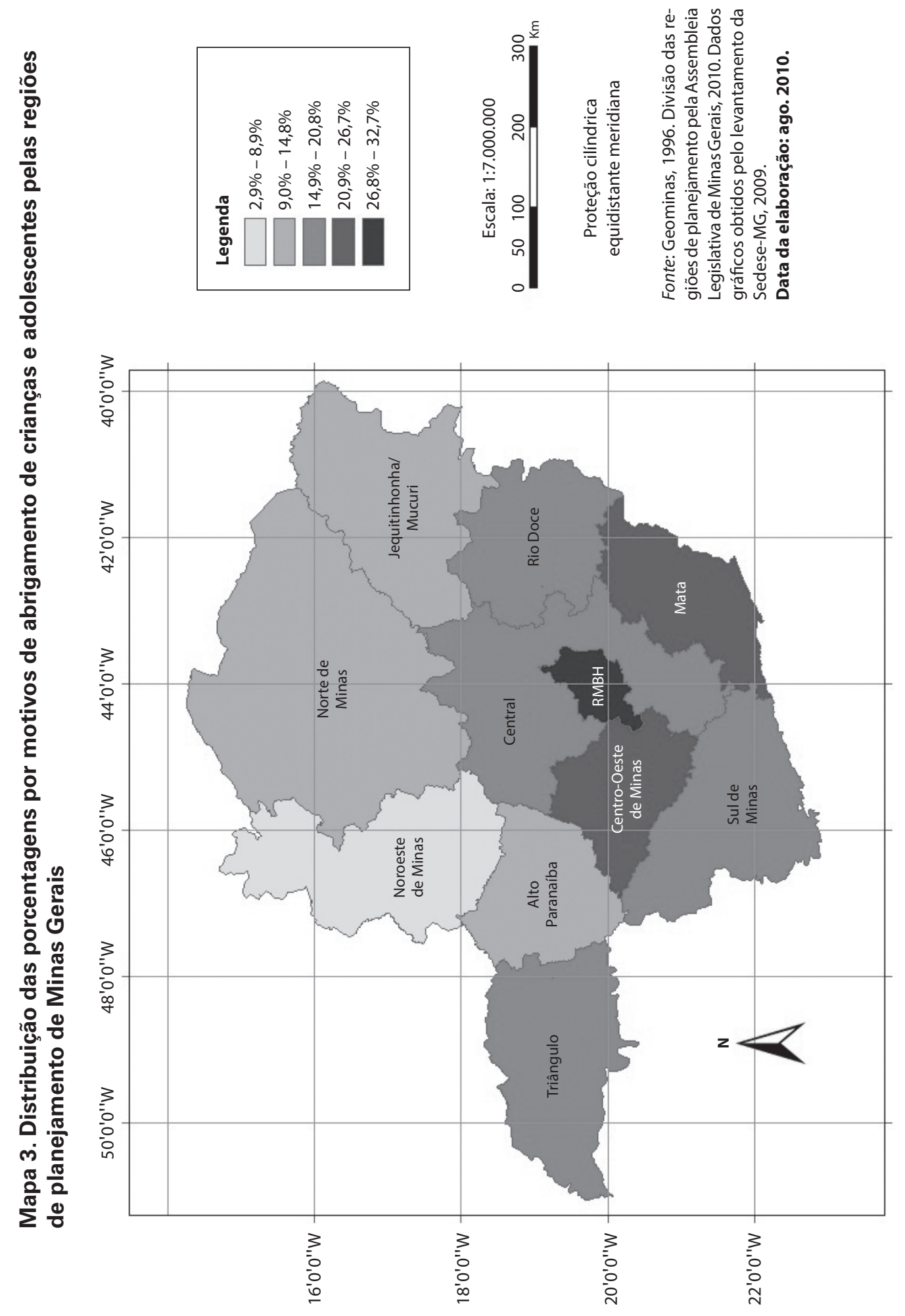




\section{Abandono}

A segunda maior frequência identificada foi o "abandono". Nesse caso, essa motivação seria caracterizada pelo desamparo da pessoa que está sob cuidado, guarda, vigilância ou autoridade e que por qualquer motivo é incapaz de defender-se dos riscos resultantes do abandono.

De acordo com o Estatuto da Criança e do Adolescente (Brasil, 1990), pratica o abandono os pais ou responsáveis que deixam, sem justa causa, de prover o sustento, a guarda e a educação dos filhos menores de dezoito anos (art. 22).

Criminalmente, o abandono pode ocorrer de duas formas: abandono material e abandono intelectual. $\mathrm{O}$ abandono material ocorre quando alguém deixa, sem justa causa, de prover a subsistência do cônjuge, filho menor de 18 anos ou inapto para o trabalho ou de ascendente inválido. $\mathrm{O}$ abandono intelectual ocorre quando alguém deixa, sem justa causa, de prover a instrução primária de filho em idade escolar (Brasil, 1940, arts. 244 e 246).

Mesmo observando-se uma distribuição mais homogênea desse motivo, as regiões que relativamente concentravam uma maior frequência foram: o centro-oeste de Minas, com mais de 20\%, seguidas pelo Triângulo, norte e noroeste de Minas. As hipóteses que determinam a maior concentração desse motivo nessas áreas ainda não estão bem esclarecidas, o que futuramente demandará mais análises. 


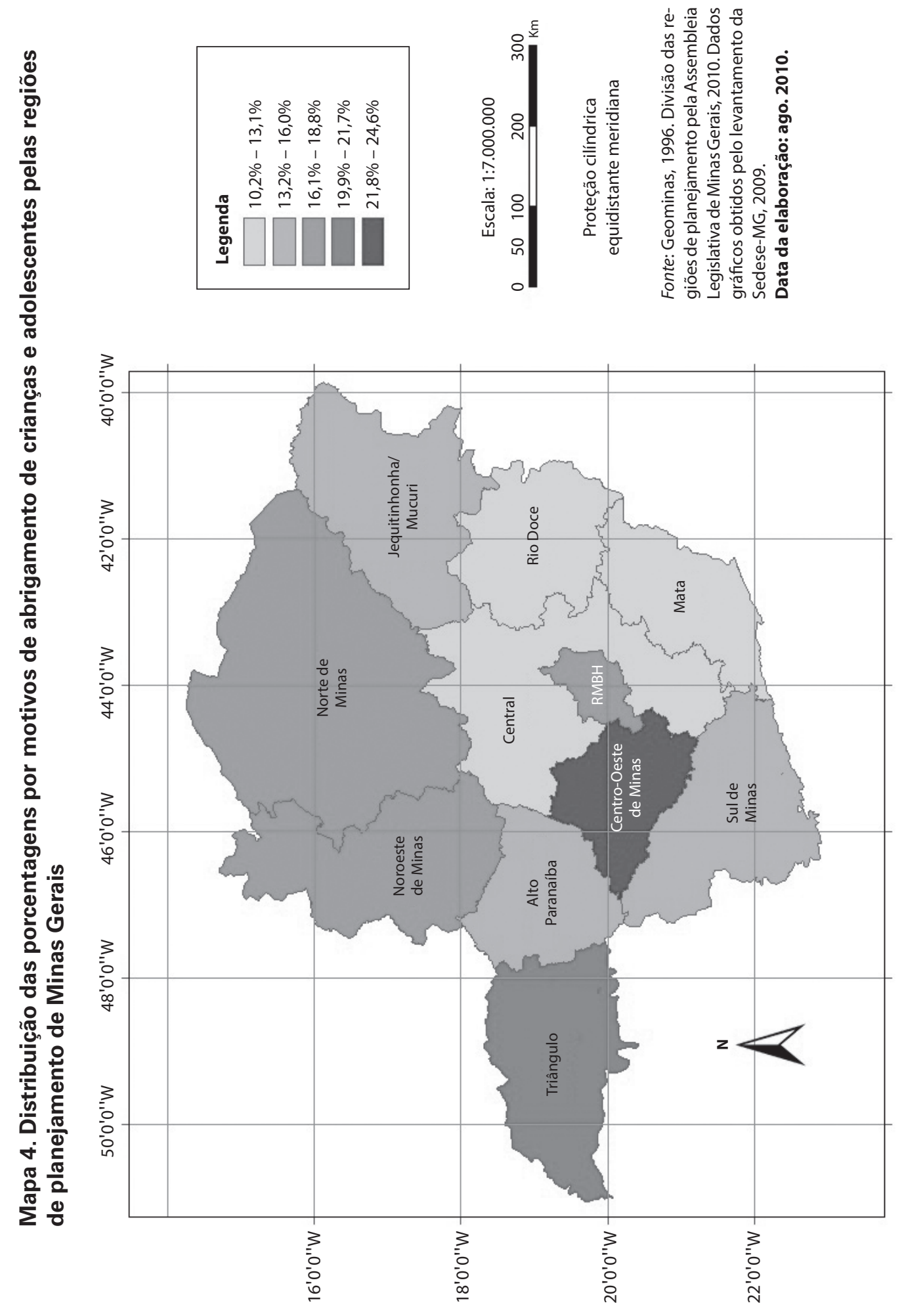




\section{Maus-tratos}

De maneira geral, a definição do que seria maus-tratos contra as crianças e jovens envolve uma extensa gama de ações e situações, que têm como resultado a ocorrência de danos à saúde física e psíquica da criança. Os maus-tratos podem ser emocionais ou físicos, sempre envolvendo formas de violência ocorrendo em diversos locais, como na família, no bairro, na escola. Exatamente por essa grande diversidade de atos e de contextos em certas circunstâncias, os maus-tratos podem ser difíceis de ser identificados, confirmados e também relatados.

Entre as causas mais comuns de maus-tratos estão os diversos tipos de violência física e doméstica, como, entre outros, as surras, o abuso de medicamentos, a privação da liberdade.

Relativamente, as maiores concentrações de crianças e adolescentes abrigados por maus-tratos ocorrem nas regiões de Jequitinhonha/Mucuri, com mais de 35,0\% do total das crianças abrigadas por esse motivo, seguidas pelas regiões norte e noroeste.

Deve-se observar que essas áreas são as que também concentram os maiores porcentuais de populações que vivem nas zonas rurais e os mais altos índices de analfabetismo do estado, aspectos que podem estar correlacionados com essa motivação. 

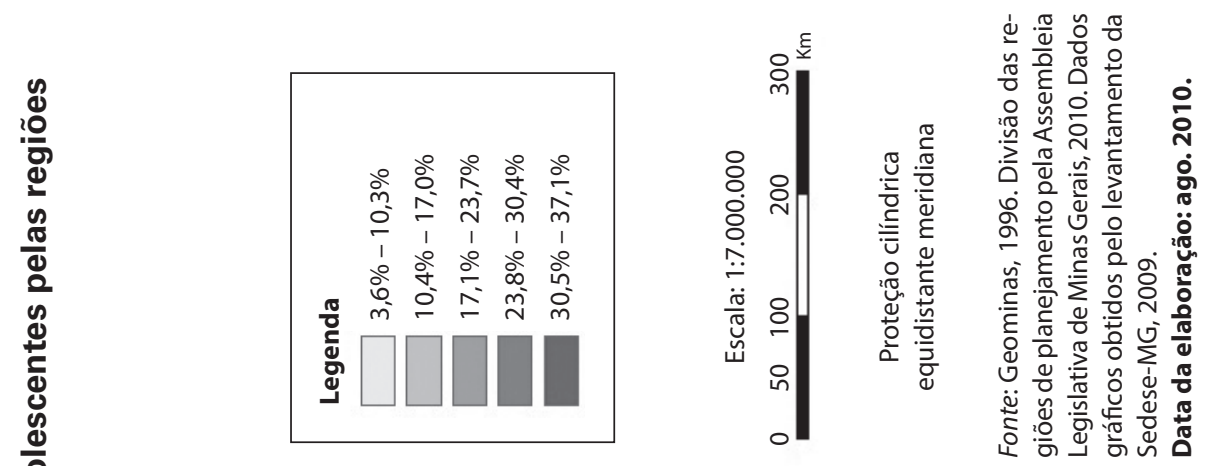

용

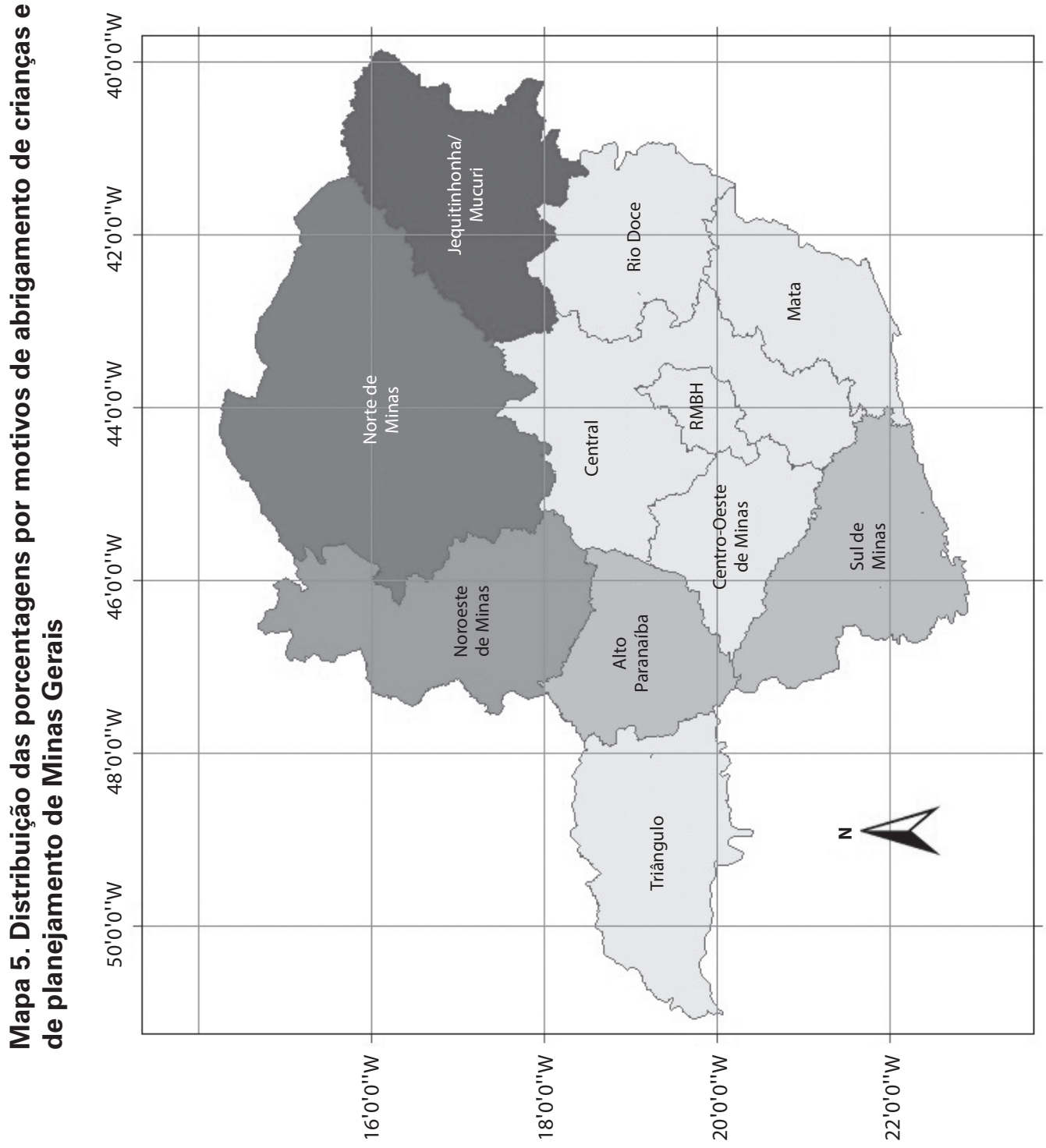




\section{Alcoolismo dos pais ou responsáveis}

Como doença, a dependência do álcool provoca diversas complicações sociais, familiares, psicológicas e de saúde, tendo, entre outras consequências, a desagregação familiar. Muitos estudos têm concluído que o álcool é a substância mais ligada às mudanças de comportamento provocadas por efeitos psicofarmacológicos e que tem como uma de suas resultantes a violência (Minayo, 1998).

Vários casos de abandono, abusos, maus-tratos e violência muitas vezes podem ser resultantes do alcoolismo na família.

O abuso do álcool é um forte agravante da violência doméstica física. A embriaguez patológica é um estado onde a pessoa que bebe torna-se extremamente agressiva, às vezes nem lembrando com detalhes o que tenha feito durante essas crises de furor e ira. (Ballone, Ortolani e Moura, 2008)

Dessa forma, o uso de álcool está relacionado a diversos problemas de saúde, o que pode implicar a internação do usuário. Este também pode ser um quadro de desagregação familiar.

Em relação ao usuário do álcool, não se pode dizer que exista um "protótipo de alcoólatra", pois o alcoolismo "não se restringe a uma etnia, estado civil, emprego, classe social e escolaridade". Por ser socialmente aceito, o álcool acaba sendo entendido como elemento de sociabilidade em todas as camadas sociais. Podem-se encontrar casos de alcoolismo entre pais, irmãos ou parentes das crianças e adolescentes (Castro e Abramovay, 2002).

Especificamente em Minas Gerais, dados da Pesquisa por Amostra de Domicílios (PAD), realizada em 2011, indicam que

aproximadamente 4 milhões de indivíduos no estado, acima de catorze anos de idade, consomem bebidas alcoólicas, mesmo que esporadicamente ou em pouca quantidade. Este número corresponde a $25 \%$ da população nesta faixa de idade. Deste percentual da população que faz uso de bebidas alcoólicas, $42 \%$ bebe uma ou duas vezes por semana, ou seja, são indivíduos que têm o hábito de beber semanalmente, e 48,5\% consomem até dez doses de bebida alcoólica no período de um mês. (FJP, 2012, p. 21)

Quando são mapeados os motivos de encaminhamento das crianças e adolescentes por uso de álcool por parte dos pais ou responsáveis, observa-se uma expressiva participação das regiões noroeste e norte de Minas, que concentram, aproximadamente, $50 \%$ do total de casos de encaminhamento por esse motivo no estado. 


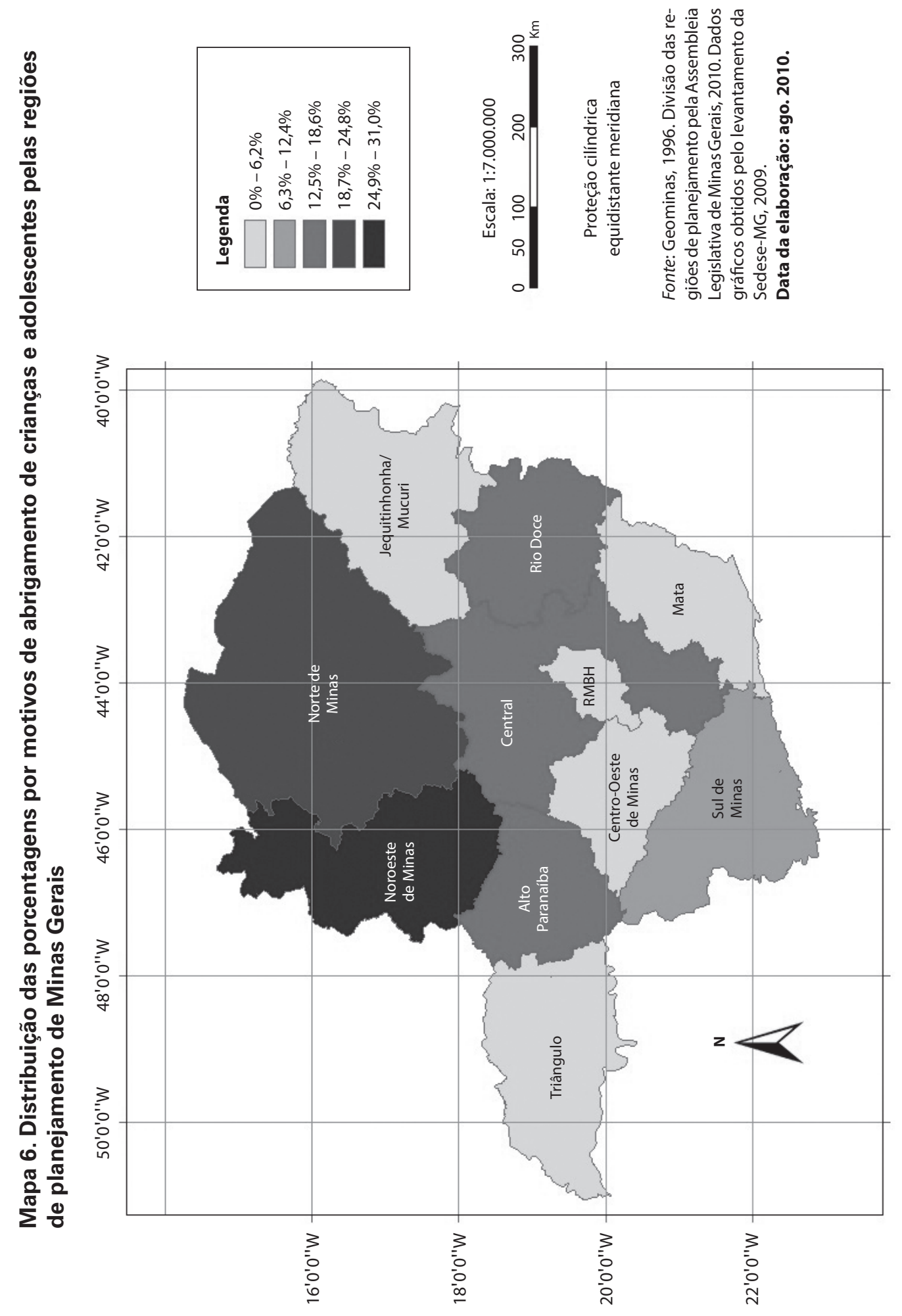


Esse fato provavelmente sugere a necessidade de ações e políticas públicas mais específicas nessas áreas, para as famílias que fazem uso do álcool, não apenas para os adultos, mas também para as crianças e principalmente para os adolescentes.

\section{Situações de risco ou vulnerabilidade}

Inicialmente deve-se observar que as crianças ou adolescentes em situação de vulnerabilidade são as que estão mais suscetíveis de terem seus direitos violados, ou seja, estão mais suscetíveis de serem expostas a danos psicológicos, físicos, morais e habitacionais devido a determinadas condições familiares e/ou sociais. Dessa maneira:

Dentre os vários enfoques dados ao termo vulnerabilidade social, observa-se um razoável consenso em torno a uma questão fundamental: a qualidade do termo deve-se a sua capacidade de captar situações intermediárias de risco localizadas entre situações extremas de inclusão e exclusão, dando um sentido dinâmico para o estudo das desigualdades, a partir da identificação de zonas de vulnerabilidades que envolvem desde os setores que buscam uma melhor posição social, até os setores médios que lutam para manter seu padrão de inserção e bem-estar... (MTE, 2007, p. 13)

A vulnerabilidade para o caso das crianças e adolescentes assume contornos específicos quando também ocorre

da passagem abrupta da infância à vida adulta; da falta de acesso à educação, trabalho, saúde, lazer, alimentação e cultura; da falta de recursos materiais mínimos para sobrevivência; da inserção precoce no mundo do trabalho; da falta de perspectivas de entrada no mercado formal de trabalho; da entrada em trabalhos desqualificados; da exploração do trabalho infantil; da falta de perspectivas profissionais e projetos para o futuro; do alto índice de reprovação e/ou evasão escolar; da oferta de integração ao consumo de drogas e de bens, ao uso de armas, ao tráfico de drogas. (Pereira, 2013, p. 1)

Em Minas Gerais, ao se observar a distribuição da causa de encaminhamento por vulnerabilidade, observa-se uma distribuição relativamente homogênea entre as diversas regiões do estado, com destaque para as regiões metropolitana de Belo Horizonte e Alto Paranaíba. Mesmo assim, essas duas áreas concentram menos de $20 \%$ dos casos observados para esse motivo. 

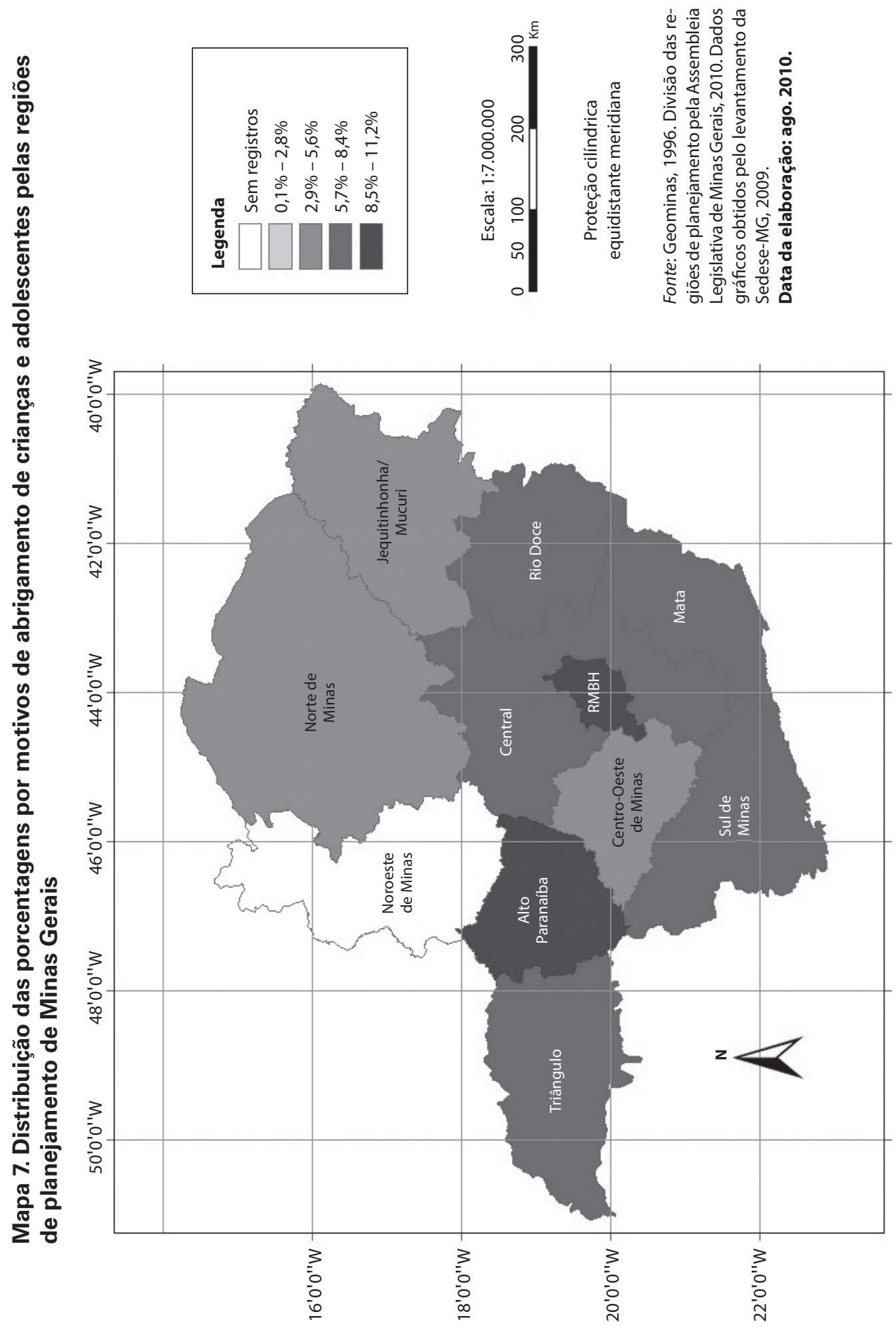


\section{Abuso e/ou suspeita ou tentativa de violência sexual ou prostituição infantil}

Normalmente, as crianças e adolescentes em circunstância de violência sexual, bem como suas famílias, acabam se encontrando em uma situação de enorme risco social. Assim, o serviço de abrigo para esses casos deve desenvolver um conjunto de ações técnicas especializadas para atendimento e proteção imediata às crianças e aos adolescentes abusados ou explorados sexualmente, assim como seus familiares, gerando condições para fortalecer a autoestima e o restabelecimento do direito à convivência familiar e comunitária.

No caso de violência sexual, as ações devem ser desenvolvidas tendo como referência as garantias constitucionais, como as do Estatuto da Criança e do Adolescente e as do Plano Nacional de Enfrentamento à Violência Sexual Contra Crianças e Adolescentes.

Em Minas Gerais, o maior número de encaminhamentos por esse motivo se concentra em regiões onde se localizam rodovias que ligam diferentes regiões do país, como é o caso da BR-040, que liga o estado do Rio de Janeiro ao Distrito Federal e que em Minas Gerais transpassa a região noroeste e Alto Paranaíba e a BR-116, que liga os estados do Rio de Janeiro à Bahia e que transpassa as regiões Rio Doce, Jequitinhonha e Mucuri. Nessas rodovias há um intenso tráfego de automóveis e caminhões que mantém uma das piores formas de exploração que é a prostituição infantil. Esse não é um problema novo no estado, porém é de difícil solução e envolve, além das medidas de proteção à criança e ao adolescente, mudança de mentalidade e comportamento das famílias e também dos usuários desse tipo de serviço. 


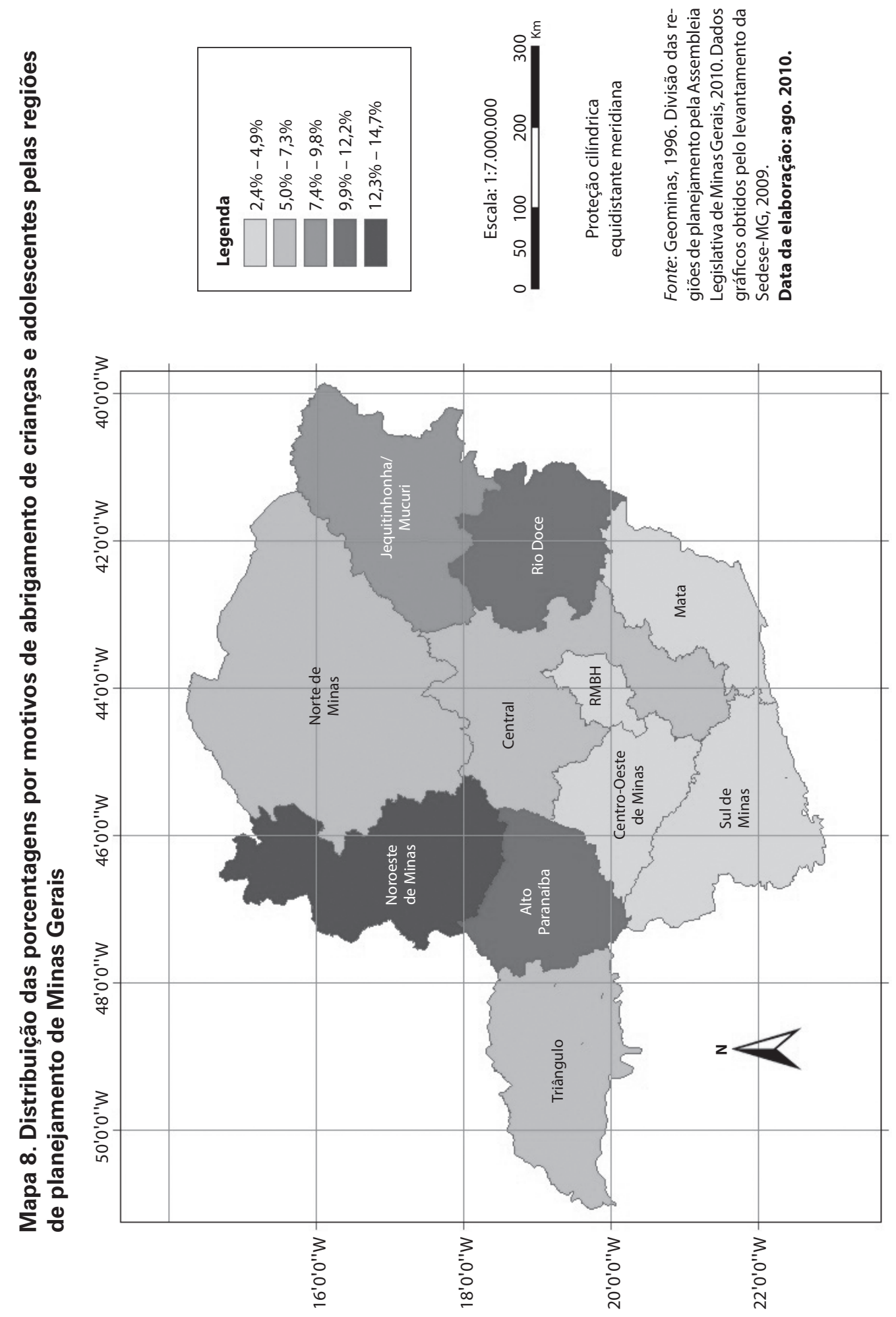




\section{Uso/tráfico de drogas pelos pais ou responsáveis}

O consumo e o tráfico de drogas podem ter diferentes consequências:

(a) $\mathrm{O}$ consumo inclui drogas lícitas e ilícitas, e ambas as modalidades acarretam alterações dos estados de consciência, possibilitando resultados direta ou indiretamente prejudiciais aos indivíduos; (b) não necessariamente o consumo de drogas está diretamente associado à violência, enquanto o tráfico está; (c) embora os usuários de drogas possam ser mais vulneráveis à violência, esta pode atingir - e frequentemente atinge - inclusive os que não usam drogas e que são contra o seu consumo. (Castro e Abramovay, 2002, p. 169)

De maneira geral, as crianças e adolescentes em cuja família um dos seus membros é usuário ou traficante de drogas estão sujeitas a um contexto de elevado risco social, especialmente se esse usuário for um dos pais ou responsáveis.

O Triângulo Mineiro é, sem dúvida, a região que concentra relativamente um maior número de crianças encaminhadas para instituições devido a esse motivo.

O Triângulo é uma das principais portas de entrada das drogas distribuídas em Minas: "É nesse trecho onde a grande maioria das apreensões estão sendo feitas. É rota que vem do centro-oeste e norte, corta o estado pelo Triângulo até chegar na capital. Suspeitamos que seja droga que venha das fronteiras" (Natálio, 2010).

O trajeto é chamado comumente de "rota caipira" e perpassa por todo o caminho da rodovia BR-262, que começa no Espírito Santo e vai até a cidade de Corumbá, na divisa com a Bolívia.

Uberlândia e Uberaba, cidades com maior população e crescimento econômico da região, são importantes pontos de armazenagem e distribuição do tráfico de drogas (Ribeiro e Carvalho, 2009). Uma das razões possíveis para esse fato é a própria posição geográfica dessas cidades, localizadas em locais estratégicos e próximos às grandes cidades do Sudeste do país, como Rio de Janeiro, São Paulo e Belo Horizonte.

Desta maneira, é possível relacionar a expressividade do motivo de encaminhamento das crianças devido ao uso/tráfico de drogas por parte dos pais e responsáveis com a característica dessa rota do mercado de drogas. Pode-se notar como esse contexto chega a afetar as famílias na região, já que muitos pais e responsáveis (tanto homens como mulheres) acabam se envolvendo com o mercado das drogas, inclusive para seu próprio consumo. 


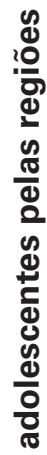
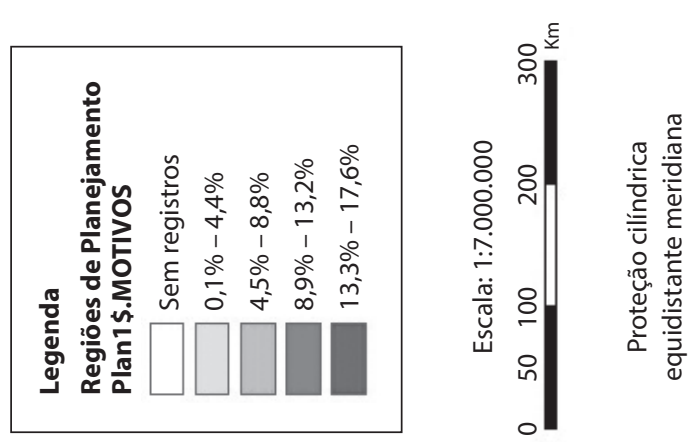

닌 $\frac{\pi}{0}$ 응 중

त

$\circ$ 凶ั

กำ

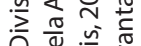

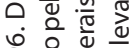

웡

- ष ॠ व

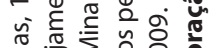

.

융 $\frac{\pi}{2}$

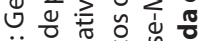

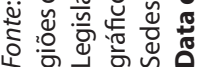

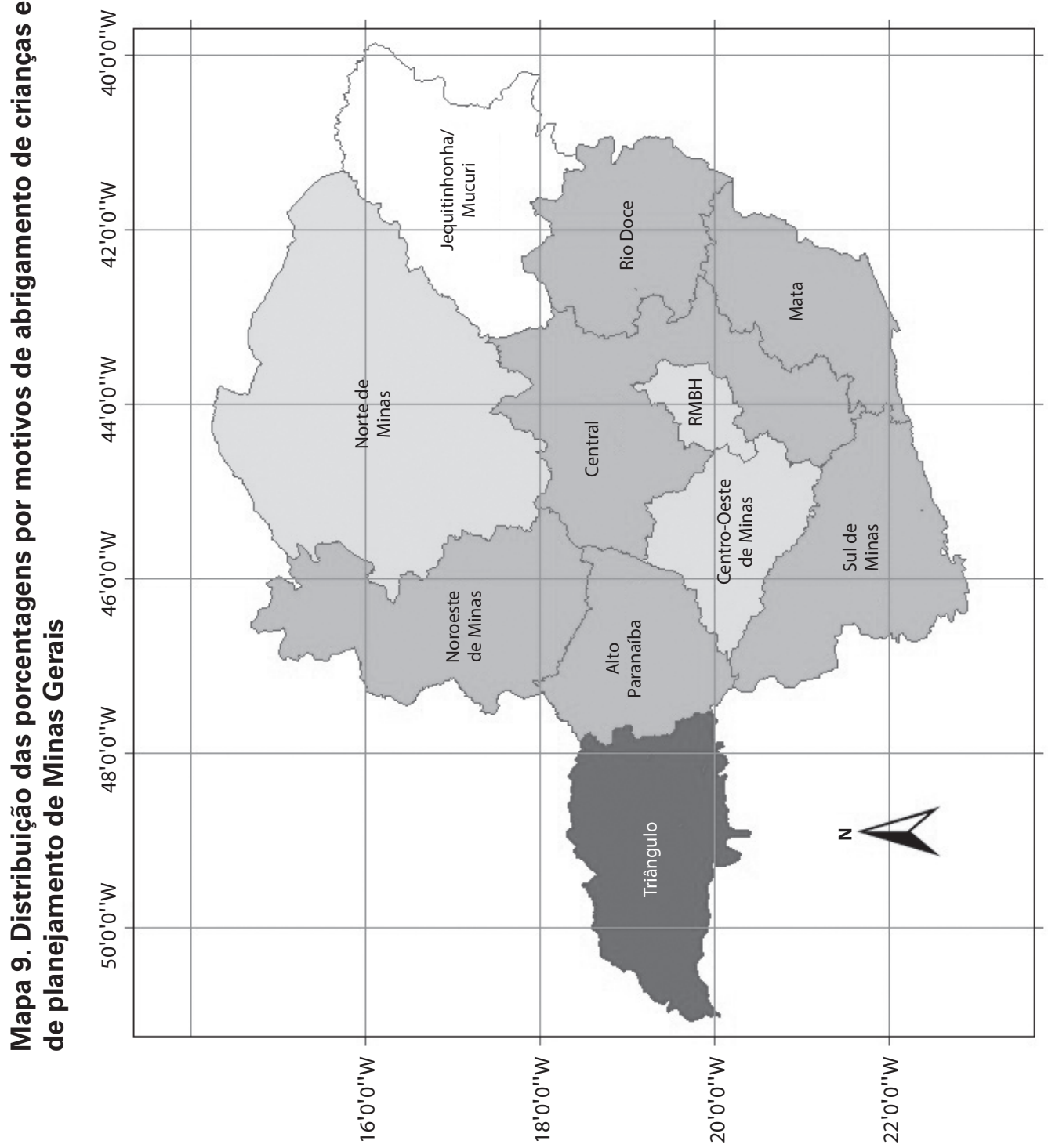




\section{Outros motivos de encaminhamento}

Como se pôde observar na Tabela 3, apresentada anteriormente, ainda existe uma série de outros motivos cujas frequências são significativas. Nesse contexto, vale destacar a ausência dos pais ou responsáveis e o motivo de encaminhamento por pobreza.

Na causa da ausência de responsáveis, os motivos basicamente se relacionam à prisão/desaparecimento/internação hospitalar ou psiquiátrica. Espacialmente, essa causalidade ocorre de forma relativamente homogênea entre as diversas regiões do estado. Aqui vale observar a necessidade da criação de serviços de atendimento, principalmente para filhos de mães presas ou internadas em casas de saúde. A expansão do tráfico e o uso de drogas têm atingindo de forma particular as mulheres, que muitas vezes acabam presas, fato que por sua vez dificulta ou mesmo impossibilita a criação dos filhos.

No caso da pobreza, em princípio, essa condição não seria motivo legal para o afastamento das crianças e dos adolescentes do seu convívio familiar. O artigo 23 do Estatuto da Criança e do Adolescente (Brasil, 1990) estabelece que a falta ou carência de recursos não caracteriza, por si só, abandono de uma criança ou de um adolescente e não pode servir de base para a decretação da perda ou suspensão do poder familiar.

No entanto, a falta de satisfação de determinadas necessidades básicas, sem dúvida alguma gera uma série de sofrimentos tanto para a família como um todo, quanto principalmente para as crianças mais jovens, levando a seu encaminhamento, sobretudo nas regiões também caracterizadas por maior carência socioeconômica.

\section{Conclusões}

Ao se definir as causas principais de encaminhamento e mapeá-las, lança-se mão de certa arbitrariedade, na medida em que se trata de uma realidade extremamente complexa, seja pelo contexto familiar, seja pelo contexto socioeconômico, aspectos que acabam se inter-relacionando. Muitas vezes, as causalidades identificadas se confundem e se sobrepõem.

Especificamente no processo de obtenção dos dados analisados, observou-se que também existem grandes problemas. No Brasil não existem procedimentos 
preestabelecidos, para a identificação de determinadas causas e contextos familiares, e a percepção de determinadas situações específicas por parte dos responsáveis pelos encaminhamentos pode variar muito, inclusive dentro de um mesmo município quando, por exemplo, existe mais de um conselho tutelar.

Por sua vez, existem deficiências na qualificação e integração dos membros dos conselhos tutelares, dos órgãos de justiça, das prefeituras municipais (Secretarias de Assistência Social) e da polícia, entidades normalmente responsáveis por identificarem as causas e a necessidade de afastamento das crianças de suas famílias. Muitas vezes as próprias instituições que acolhem essas crianças também não registram adequadamente os motivos de encaminhamento.

Mesmo com todos esses desafios, a pesquisa permitiu encontrar quadros sociais precários nas diversas regiões do estado, que se repercutem nos processos de desagregação familiar e, consequentemente, nas condições de vida de todos os envolvidos.

Algumas causas de encaminhamentos apresentam claramente uma concentração regional, como, por exemplo, negligência na região metropolitana de Belo Horizonte, maus-tratos na região do Vale do Jequitinhonha/Mucuri e norte de Minas, abandono no centro-oeste e Triângulo Mineiro, alcoolismo dos pais/responsáveis no noroeste e norte de Minas, uso e/ou tráfico de drogas dos pais e responsáveis no Triângulo Mineiro, e exploração sexual nas regiões contadas pelas rodovias BR-040 e BR-116.

A partir dessas constatações, pode-se entender que se faz necessário o desenvolvimento de políticas públicas específicas que deverão ir de encontro às necessidades das famílias e de acordo com as características regionais observadas.

\section{Recebido em 8/10/2013 - Aprovado em 2/12/2013}

\section{Referências bibliográficas}

BALlONE, G. J.; ORTOLANI, V.; MOURA, E. C. Violência doméstica, PsiqWeb, 2008. Disponível em: <www.psiqweb.med.br>. Acesso em: 21 jun. 2013.

BRASIL. Decreto-lei n. 2.848, de 7 de dezembro de 1940. . Estatuto de Criança e do Adolescente (ECA), Lei Federal n. 8.069/1990. 
CASTRO, Mary Garcia; ABRAMOVAY, Miriam. Jovens em situação de pobreza, vulnerabilidades sociais e violências. Cadernos de Pesquisa Fundação Carlos Chagas, São Paulo, n. 116, jul. 2002.

FUNDAÇÃO JOÃO PINHEIRO (FJP). Pesquisa abrigos em Minas Gerais. Relatório final, Belo Horizonte, 2009. (Mimeo.)

. Hábitos de vida saudável. Boletim PAD-MG, Belo Horizonte, ano 1, n. 4, nov. 2012.

HYDE, Justeen. From home to street: understanding young people's transitions into homelessness. Journal of Adolescence, Filadélfia, n. 28, p. 171-183, 2005.

MINAYO, Maria Cecília de Souza; DESLANDES, Suely Ferreira. A complexidade das relações entre drogas, álcool e violência. Cadernos de Saúde Pública, Rio de Janeiro, v. 14, n. 1, jan. 1998.

MINISTÉRIO DO TRABALHO E EMPREGO (MTE). Aspectos conceituais da vulnerabilidade social. Convênio TEM-Dieese, 2007. Disponível em: <www.mte.gov.br/observatorio/sumario_2009_textov1.pdf>. Acesso em: 13 mar. 2013.

MIRABETE, Júlio Fabrini. Manual de direito penal. São Paulo: Atlas, 1980. v. 1.

NATÁLIO, R. Uberaba na rota do tráfico. Jornal de Uberaba, Uberaba, caderno Cidade, 25 jul. 2010.

PEREIRA, Sandra; ENI F. N. Crianças e adolescentes em contexto de vulnerabilidade social: articulação de redes em situação de abandono ou afastamento do convívio familiar. Aconchego-DF, 2013. (Mimeo.) Disponível em: <www.aconchegodf.org.br/biblioteca/artigos/artigo01.pdf>. Acesso em: 3 jun. 2013.

RIBEIRO, M.; CARVALHO, C. PF faz operação para combater tráfico de drogas em cinco estados do país. $O$ Globo, caderno Cidades, 28 out. 2009.

SECRETARIA DE DESENVOLVIMENTO SOCIAL DE MINAS GERAIS (SEDESE). Banco de Dados. Pesquisa abrigos em Minas Gerais. Belo Horizonte, 2009.

SILVA, Enid. R. (Coord.). O direito à convivência familiar e comunitária: os abrigos para crianças e adolescentes no Brasil. Brasília: Ipea/Conanda, 2004.

WOODS, Dorian, R. Family policy in transformation: US and UK policies. London: Palgrave Macmillan, 2012. 